\title{
A Phase II Study Alternating Erlotinib With Second-line mFOLFOX6 or FOLFIRI for Metastatic Colorectal Cancer
}

\author{
MATTHEW R. KEARNEY ${ }^{1 *}$, EMERSON Y. CHEN ${ }^{1 *}$, GINA M. VACCARO ${ }^{1}$, JOHN STROTHER $^{3}$, ANDREA BURT $^{1}$, \\ KENDRA TODD ${ }^{1}$, JEFF DONOVAN ${ }^{1}$, KERSTIN M. KAMPA-SCHITTENHELM ${ }^{2}$ and CHARLES D. LOPEZ ${ }^{1}$ \\ ${ }^{1}$ Division of Hematology and Medical Oncology, Knight Cancer Institute, \\ Oregon Health and Science University, Portland, OR, U.S.A.; \\ ${ }^{2}$ Department of Oncology, Hematology, Rheumatology, Clinical Immunology and Pulmonology, \\ University Hospital Tübingen, Tübingen, Germany; \\ ${ }^{3}$ Hematology Oncology of Salem, Salem, OR, U.S.A.
}

\begin{abstract}
Background: Based on our pre-clinical data, we hypothesized that sequencing chemotherapy with erlotinib would increase the tumor response rate in patients with metastatic colorectal cancer. Patients and Methods: A phase II trial (planned $n=58$ ) using second-line therapy for metastatic colorectal cancer with either oxaliplatin-based (mFOLFOX6) or irinotecan-based (FOLFIRI) combination chemotherapy and $100 \mathrm{mg}$ erlotinib daily on days 3-8 after each infusion (days 1 and 2) every 14 days. The primary endpoint was the response rate compared to the historical response rate. Results: The FOLFIRI/erlotinib arm met the pre-specified response rate criteria of at least $10 \%$ to expand accrual to the intended sample size. The trial was halted after an interim safety analysis $(n=11)$ due to excess grade 3 neutropenia, dose reductions and treatment delays. Grade 3 or 4 neutropenia was observed in $64 \%$ of patients. The response rate was $18 \%$. Conclusion: In second-line treatment for metastatic colorectal cancer, mFOLFOX6 or FOLFIRI with erlotinib in a sequence-dependent fashion is not feasible despite potential promising activity.
\end{abstract}

Colorectal cancer is the third most common type of adult cancer in the world, with an estimated 1.8 million cases and 881,000 deaths annually by the GLOBOCAN estimate in 2018

This article is freely accessible online.

*These Authors contributed equally to this study.

Correspondence to: Charles D. Lopez, MD, Ph.D., Associate Professor of Medicine, Oregon Health and Science University, 3181 SW Sam Jackson Park RD, L586, Portland, OR 97239, U.S.A. Tel: +1 5034948321, Fax: +1 5034189719, e-mail: lopezc@ohsu.edu

Key Words: Erlotinib, colorectal cancer, 5-fluorouracil, 5-FU, irinotecan, oxaliplatin, epidermal growth factor receptor, EGFR.
(1). While more than $20 \%$ of these patients are diagnosed with metastatic disease, advancement in systemic treatment options have improved their expected median survival from 11-12 months with fluoropyrimidine alone to approximately 2.5 years with modern combination therapies $(2,3)$. Combination chemotherapy of either oxaliplatin, 5-fluorouracil and leucovorin (FOLFOX) or irinotecan, 5-fluorouracil, and leucovorin (FOLFIRI) has similar response rates and survival outcomes in the first-line metastatic setting (3-5). Moreover, these chemotherapy platforms have further incorporated biological agents, such as bevacizumab or monoclonal antibodies to epidermal growth factor receptor (EGFR), thereby improving response rates to approximating $60 \%$ in the first-line metastatic setting, as well as prolonging survival endpoints $(3,5,6)$. However, second-line chemotherapy platforms using the alternate chemotherapy regimen with a biological agent, typically demonstrates less clinical activity and lower response rates of 6-35\% (7-9).

Given the expanding repertoire of biological agents, tyrosine kinase inhibitors (TKIs), and most recently immune checkpoint inhibitors for the treatment of metastatic colorectal cancer, there is a continued need to optimize second-line treatment options by integrating chemotherapy with more targeted approaches. This is particularly true as our knowledge based on colorectal cancer subtypes increases (10). Indeed, tumor location and molecular biomarkers, such as extended $R A S$ mutations [testing beyond KRAS proto-oncogene, GTPase (KRAS) exon 2 to also include both KRAS and NRAS proto-oncogene, GTPase (NRAS) from exons 2 through 4], BRaf proto-oncogene, serine/threonine kinase $(B R A F)$ mutations, and mismatch repair deficiency, are also increasingly used to predict activity to specific therapeutic agents. EGFR is a receptor that activates signaling pathways to promote cell proliferation and is frequently overexpressed in colorectal adenomas and cancer (11-13). Monoclonal antibodies to EGFR, such as cetuximab and panitumumab, 
inhibit this pathway by directly blocking the receptor while erlotinib, an orally administered TKI, targets EGFR by preventing receptor auto-phosphorylation intracellularly. However, tumors with $R A S$ and BRAF V600E mutations confer resistance to anti-EGFR-based therapies by maintaining constitutively active signaling proteins downstream of EGFR. In fact, only patients who have wild-type $R A S$ tumors have any clinical benefit from anti-EGFR therapy (14).

When erlotinib was first studied in clinical trials for metastatic colorectal cancer, it did not lead to any objective response as a single agent in unselected patients as $R A S$ testing was not available at that time (15). Interestingly, gefitinib, another small molecule EGFR inhibitor, in combination with chemotherapy demonstrated feasibility in single-arm phase II studies $(16,17)$, although follow-up confirmatory studies were not completed. Subsequent erlotinib tolerability studies found that continuous erlotinib dosing with FOLFIRI or FOLFOX caused significant neutropenia, diarrhea, mucositis, fatigue, and disfiguring rash (18-20). Preclinical studies, however, supported combining EGFR TKI with cytotoxic agents, as conventional chemotherapy may lead to up-regulation of EGFR expression to resist apoptosis and cell damage from chemotherapy (2123). In vitro studies also demonstrated that anti-EGFR TKI can more effectively induce cell death when given after cytotoxic agents, also known as sequence-dependent inhibition (24). Based on the findings of these pre-clinical and early safety studies, we hypothesized that sequential dosing and scheduling of anti-EGFR TKI in combination with chemotherapy for metastatic colorectal cancer is critical for potentiating optimal antitumor effects while avoiding additive toxicity seen in the early clinical trials. We performed pre-clinical testing to demonstrate that alternative sequencing of EGFR TKI with cytotoxic chemotherapy enhanced colorectal tumor cell apoptosis. We then conducted a phase II clinical trial in patients with metastatic colorectal cancer being treated with either second-line FOLFOX or FOLFIRI to also receive 6 days of erlotinib after each administration of chemotherapy infusion in an alternating, sequence-dependent fashion.

\section{Patients and Methods}

Pre-clinical model. Human colorectal cancer cell lines isogenic for TP53 and KRAS mutation (HCT116) was used to determine the optimal timing of EGFR inhibition and chemotherapy. Oxaliplatin chemotherapy was dosed at concentration of $60 \mu \mathrm{M}$, and erlotinib was dosed at $12.5 \mathrm{nM}$. Six types of treatments of HCT116 cells in culture, with each in triplicate, were completed: untreated, oxaliplatin alone, erlotinib alone, both drugs concurrently, oxaliplatin first for 24 hours followed by erlotinib, and erlotinib first for 24 hours followed by oxaliplatin. Apoptosis measurement by flow cytometry and annexin V staining was carried out 72 hours after initial treatment exposure.
Study design and patients. Following pre-clinical data, the clinical study was a non-randomized two-centered phase II trial (including Salem Hospital) that assigned treatment intervention based on patients' first-line treatment, FOLFOX or FOLFIRI, and with the addition of erlotinib for all (NCT00642746). Patients who were 18 years or older with biopsy-proven, unresectable metastatic colorectal adenocarcinoma that had progressed on first-line FOLFOX or FOLFIRI with or without bevacizumab were eligible for enrollment. A washout period of at least 4 weeks was required if a biological agent was used previously. Monoclonal antibodies to EGFR had not yet been approved for use in front-line therapy at the time of the study. The role of $R A S$ mutation as a predictive biomarker became known only after the study had begun. Eligible patients had performance status of 0 or 1 with adequate organ function and pretreatment laboratory parameters to receive standard second-line FOLFOX or FOLFIRI. Patients were excluded if they had prior treatment with an EGFR TKI, prior second-line chemotherapy, brain metastases, other recent malignancies, significant co-morbidities, anemia with hemoglobin $<9.0 \mathrm{~g} / \mathrm{dl}$, uncontrolled diarrhea, bowel obstruction, inability to take oral medications, human immunodeficiency virus infection, or were pregnant.

Treatment Interventions. Patients were treated using standard second-line modified FOLFOX6 (mFOLFOX6) or FOLFIRI that they had not received in the first-line and a 6-day course of erlotinib immediately following each chemotherapy infusion. Each cycle was every 28 days with two rounds of chemotherapy followed by a $6-$ day course of erlotinib in an alternating fashion. Specifically, mFOLFOX6 was administered as $85 \mathrm{mg} / \mathrm{m}^{2}$ oxaliplatin i.v. on days 1 and $15,400 \mathrm{mg} / \mathrm{m}^{2}$ leucovorin on days 1 and 15 , and $400 \mathrm{mg} / \mathrm{m}^{2}$ fluorouracil i.v. bolus on days 1 and 15 , followed by $2,400 \mathrm{mg} / \mathrm{m}^{2}$ continuous infusion over 46 hours on days 1-3 and 15-17. Likewise, FOLFIRI was administered by $180 \mathrm{mg} / \mathrm{m}^{2}$ irinotecan on days 1 and $15,400 \mathrm{mg} / \mathrm{m}^{2}$ leucovorin on days 1 and 15 , and $400 \mathrm{mg} / \mathrm{m}^{2}$ fluorouracil i.v. bolus on days 1 and 15 , followed by $2,400 \mathrm{mg} / \mathrm{m}^{2}$ continuous infusion over 46 hours on days 1-3 and 15-17. Erlotinib was dosed at $100 \mathrm{mg}$ orally once daily and given on days 3-8 and 17-22. Days 9-14 and 23-28 were treatment-free days to allow erlotinib clearance prior to the next chemotherapy administration.

Outcome measures. The primary study endpoint was the radiographic response rate according to the Response Evaluation Criteria in Solid Tumors (RECIST) 1.0 criteria (25). Secondary study endpoints were time to progression (TTP), progression-free survival, and toxicity and safety according to National Cancer Institute Common Toxicity Criteria version 3.0 (26). The screening assessment was completed within 21 days before starting the first treatment cycle. Patients underwent clinic visits with standard laboratory monitoring every 14 days before each chemotherapy infusion. Evaluation with computed tomographic imaging occurred every two cycles, or approximately every 2 months. Tumors were optionally obtained to test for EGFR sequencing and $K R A S$ exon 2 if available.

Safety. Erlotinib was reduced to $50 \mathrm{mg}$ daily (first level) for known grade 3 dermatological, hepatic, or gastrointestinal toxicities. If patients were not able to tolerate first level dose reduction, erlotinib was reduced to $25 \mathrm{mg}$ daily (second level). If patients were unable to tolerate two dose reductions, developed erlotinib-associated interstitial lung disease, or had any related grade 4 adverse events, erlotinib was discontinued. Study treatments were also discontinued 


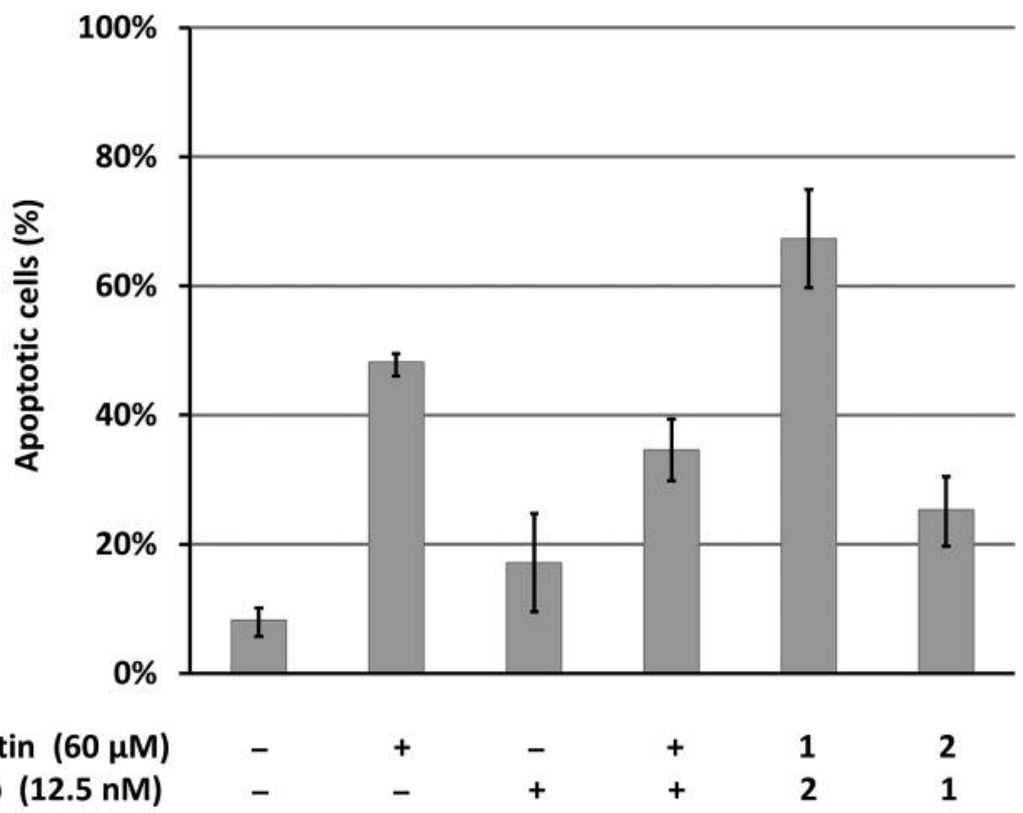

Figure 1. In vitro effects of oxaliplatin and erlotinib schedule/sequencing on the percentage HCT116 human colorectal cancer cells undergoing apoptosis, as measured by annexin V staining and flow cytometry in (y-axis). HCT116 cells were untreated, or treated with oxaliplatin alone, erlotinib alone, concurrent oxaliplatin and erlotinib, oxaliplatin followed by erlotinib, or erlotinib followed by oxaliplatin. Experiments were performed in triplicate, and data are means with error bars indicating standard deviation. The second drug was added 24 hours after washing out of first drug in sequential experiments. Apoptosis was measured 72 hours after initial drug exposure. - Drug absent $;+$ drug present $(+$ for both drugs indicates concurrent therapy); 1 or 2 : order of drugs in sequential therapy experiments.

for unacceptable toxicity, more than three consecutive dose delays at patient or physician request, or progressive disease.

Statistical analysis. The study was developed as a Simon's optimal two-stage design with two parallel independent arms, mFOLFOX6 plus erlotinib (mFOLFOX/E) and FOLFIRI plus erlotinib (FOLFIRI/E). Each arm was designed with $80 \%$ power to detect an increased response rate with the addition of erlotinib to chemotherapy by using predicted historical response rates for second-line mFOLFOX6 and FOLFIRI, using Fisher's exact test with $5 \%$ significance. Specifically, mFOLFOX/E was predicted to increase the response rate from 10 to $30 \%$, and FOLFIRI/E, from $5-20 \%$, thereby estimating a required sample size of 29 patients for each arm. However, when one treatment arm enrolled 10 patients, an interim analysis for that arm was required before continuing accrual for all 29 patients in that arm. At least a partial response by RECIST criteria was required in more than two out of 10 patients in the $\mathrm{mFOLFOX/E}$ arm and one out of 10 patients in the FOLFIRI/E arm to continue enrollment. Each treatment intervention would be considered promising if six or more out of 29 patients in the mFOLFOX/E arm or four or more out of 29 patients in the FOLFIRI/E arm had at a least partial response by RECIST criteria.

\section{Results}

Because EGFR TKIs can induce $\mathrm{G}_{1} / \mathrm{G}_{0}$ cell-cycle arrest modulating the apoptotic threshold $(24,27,28)$, we utilized pre-clinical models with the human colorectal cancer cell line HCT116 (KRAS-mutant) to determine the importance of scheduling EGFR TKI inhibition after cytotoxic therapy with respect to induction of tumor cell death before launching the phase II clinical trial (Figure 1). Oxaliplatin-induced tumor cell killing was first established at a dose and time point that caused approximately $45 \%$ apoptosis compared to baseline apoptosis. Interestingly, concurrent oxaliplatin and erlotinib reduced apoptotic tumor cell death compared to oxaliplatin alone. However, when colorectal cancer cells were sequentially treated with oxaliplatin first followed by washout and then with erlotinib, apoptosis significantly increased compared to that with oxaliplatin alone, erlotinib alone, or concurrent oxaliplatin with erlotinib (Figure 1). In contrast, dosing with erlotinib first followed by oxaliplatin dramatically inhibited apoptosis compared to the opposite sequence as well as to oxaliplatin alone (Figure 1). Small molecule EGFR TKI inhibition induced a $\mathrm{G}_{0} / \mathrm{G}_{1}$ cell-cycle arrest in HCT116 cells that inhibited chemotherapy-induced apoptosis (data not shown). Taken together, these pre-clinical data supported the rationale for sequence chemotherapy (mFOLFOX6 or FOLFIRI) followed by erlotinib in the second-line treatment of patients with metastatic colorectal cancer. Dosing and schedule was designed to permit sufficient washout of erlotinib (based on its half-life of 36 hours) prior to the next chemotherapy administration. 
Following the pre-clinical results, the phase II study was activated in March 2008 and closed in December 2011 after an interim safety analysis. After obtaining written consent from 16 patients, two patients withdrew consent and three patients did not meet screening criteria. Eleven patients were enrolled in the study: 10 on the FOLFIRI/E arm, and one on the $\mathrm{mFOLFOX/E}$ arm. The majority of patients were over the age of 60 years and Caucasian. Table I summarizes the baseline characteristics. Ten patients received first-line oxaliplatin-based therapy while one patient received first-line FOLFIRI. Five patients (45\%) obtained a partial response to first-line chemotherapy prior to study enrollment, including the patient who received FOLFIRI. Bevacizumab was used in the first-line setting in six (55\%) patients.

The primary objective was to determine response rate in each treatment arm. Table II summarizes the response rates and TTP of the FOLFIRI/E and mFOLFOX/E arms. Within the FOLFIRI/E arm $(n=10)$, one patient had a partial response, one had a mixed response, four had stable disease, and four had progressive disease. The FOLFIRI/E arm met the pre-specified criteria of at least $10 \%$ response rate to expand accrual to the intended sample size, while the $\mathrm{mFOLFOX/E}$ arm had not yet enrolled enough patients. The single patient in the $\mathrm{mFOLFOX/E}$ arm demonstrated a partial response. KRAS exon 2 mutation testing became available only after study initiation. Six patients had wild-type $K R A S$, and five had KRAS mutations, as shown in Table II. Both patients with partial responses had wild-type KRAS. The median TTP for patients in the FOLFIRI/E arm was 2.7 (range $=0.5-6.9$ ) months, and TTP for the mFOLFOX/E patient was 4.1 months.

Our data on safety, specifically grade 3 and 4 toxicities, are summarized in Table III. Cytopenia, oral pain, fatigue, nausea, diarrhea, and rashes were all observed. The most common grade 3 or 4 adverse events were neutropenia in seven (64\%) patients, followed by mucositis and diarrhea, both seen in two (18\%) patients. Four (36\%) patients received outpatient intravenous fluids, and two (18\%) patients required blood transfusions. Five (45\%) patients required filgrastim. Nine (82\%) patients had cycle delays due to toxicity, and three (27\%) patients required erlotinib dose reductions. Three (27\%) patients experienced grade 3 or 4 adverse events requiring treatment discontinuation. No deaths were observed during the study. The median time to any grade 3 or 4 adverse event was 14 days (range $=0-104$ days). As summarized in Table IV, the median duration of chemotherapy administered was 2 (range $=0.5-6$ ) months, and the median days of erlotinib administered was 30 (range $=6-71$ ) days.

An unplanned interim safety analysis was performed at the investigators' discretion due to frequent neutropenia resulting in cycle delays and dose reductions. This led to study termination due to excess grade 3 neutropenia, excess dose reductions and treatment delays.
Table I. Baseline characteristics of study patients $(N=11)$.

\begin{tabular}{|c|c|}
\hline & Value \\
\hline \multicolumn{2}{|l|}{ Age, years } \\
\hline Median (range) & $64(27-73)$ \\
\hline \multicolumn{2}{|l|}{ Gender } \\
\hline Male & $4(36 \%)$ \\
\hline Female & $7(64 \%)$ \\
\hline \multicolumn{2}{|l|}{ Race/ethnicity } \\
\hline Non-Hispanic White & $10(91 \%)$ \\
\hline \multicolumn{2}{|l|}{ ECOG performance status } \\
\hline 0 & $4(36 \%)$ \\
\hline 1 & $7(64 \%)$ \\
\hline \multicolumn{2}{|l|}{ Cancer staging } \\
\hline Stage IV at first diagnosis & $10(91 \%)$ \\
\hline \multicolumn{2}{|l|}{ Location of primary tumor } \\
\hline Right-sided (cecum to transverse colon) & $5(45 \%)$ \\
\hline Left-sided (descending colon to rectum) & $6(55 \%)$ \\
\hline \multicolumn{2}{|l|}{ Site of metastases } \\
\hline Liver & $9(82 \%)$ \\
\hline Lung & $7(64 \%)$ \\
\hline Intra-abdominal & $6(55 \%)$ \\
\hline \multicolumn{2}{|l|}{ Prior first-line chemotherapy } \\
\hline Oxaliplatin-based & $10(91 \%)$ \\
\hline Irinotecan-based & $1(9 \%)$ \\
\hline \multicolumn{2}{|l|}{ Prior response } \\
\hline Partial response & $5(45 \%)$ \\
\hline Mixed response & $3(27 \%)$ \\
\hline Stable disease & $0(0 \%)$ \\
\hline Progressive disease & $3(27 \%)$ \\
\hline \multicolumn{2}{|l|}{ Baseline laboratory data } \\
\hline \multicolumn{2}{|l|}{ AST (U/1) } \\
\hline Median (range) & $33(16-55)$ \\
\hline \multicolumn{2}{|l|}{$\operatorname{ALT}(\mathrm{U} / 1)$} \\
\hline Median (range) & $20.5(7-54)$ \\
\hline \multicolumn{2}{|l|}{$\operatorname{ALP}(\mathrm{U} / 1)$} \\
\hline Median (range) & $97(50-273)$ \\
\hline \multicolumn{2}{|l|}{ T-Bilirubin (mg/dl) } \\
\hline Median (range) & $0.7(0.3-1.4)$ \\
\hline \multicolumn{2}{|l|}{ Albumin $(\mathrm{g} / \mathrm{dl})$} \\
\hline Median (range) & $3.4(1.3-4.2)$ \\
\hline \multicolumn{2}{|l|}{ Creatinine (mg/dl) } \\
\hline Median (range) & $0.6(0.5-0.9)$ \\
\hline \multicolumn{2}{|l|}{$\mathrm{WBC}\left(\times 10^{3} / \mu \mathrm{l}\right)$} \\
\hline Median (range) & $6.2(3.8-12.6)$ \\
\hline \multicolumn{2}{|l|}{ Hct $(\mathrm{g} / \mathrm{dl})$} \\
\hline Median (range) & $37.9(32-44)$ \\
\hline \multicolumn{2}{|l|}{ Plt $\left(\times 10^{3} / \mu \mathrm{l}\right)$} \\
\hline Median (range) & $269(110-497)$ \\
\hline \multicolumn{2}{|l|}{$\mathrm{CEA}(\mathrm{ng} / \mathrm{ml})$} \\
\hline Median (range) & $67.4(1.6-1371)$ \\
\hline
\end{tabular}

ECOG: Eastern Cooperative Oncology Group; AST: aspartate aminotransferase; ALT: alanine aminotransferase; ALP: alkaline phosphatase; T-Bilirubin: total bilirubin; WBC: white blood cell count; Hct: hematocrit; Plt: platelet; CEA: carcinoembryonic antigen.

\section{Discussion}

We observed a combined response rate of 18\% (two out of 11 patients) during the first stage of accrual. For the FOLFIRI/E arm $(n=10)$, this met the pre-specified criteria of 
Table II. Objective response rate $(N=11)$.

\begin{tabular}{lcc}
\hline Response & FOLFIRI+erlotinib & mFOLFOX+erlotinib \\
\hline Complete response & 0 & 0 \\
Partial response & $1(\mathrm{wt})$ & $1(\mathrm{wt})$ \\
Stable disease & 4 (wt: 2, mut: 2$)$ & 0 \\
Mixed response & 1 (wt) & 0 \\
Progressive disease & 4 (wt: 1, mut: 3$)$ & 0 \\
TTP (median/range) & $2.7(0.5-6.9)$ months & 4.1 months \\
\hline
\end{tabular}

FOLFIRI: Irinotecan, 5-fluorouracil, and leucovorin; mFOLFOX: oxaliplatin, 5-fluorouracil, and leucovorin; wt: wild-type $K R A S$; mut: mutant KRAS.

at least $10 \%$ response rate to expand accrual to the intended sample size $(n=29)$. However, excessive toxicity resulted in nine out of 11 participants experiencing cycle delays and three out of 11 participants experiencing treatment discontinuation secondary to side-effects. Additionally, after this trial initiated, the widespread adoption of approved biological agents, such as bevacizumab, cetuximab, and panitumumab, in the second-line treatment setting led to slow accrual. Thus, the study was terminated due to the unlikelihood that the primary endpoints would be met.

Subsequent to our trial, investigators have tested capecitabine plus oxaliplatin in combination with continuous erlotinib, a strategy that allows immediate dose interruption and adjustment based on toxicity. Standard capecitabine plus oxaliplatin every 21 days along with erlotinib led to response rates of $25-28 \%$ with tolerable toxicity $(29,30)$. However, capecitabine plus irinotecan along with continuous erlotinib was found to have a high incidence of diarrhea (31). Moreover, another trial combining capecitabine with erlotinib recorded high discontinuation rates due rash and diarrhea (32). Consistent with the theme of excess toxicities, another EGFR TKI, gefitinib, was found to have a similar toxicity profile resulting in $23.1 \%$ withdrawing from the study (33). Although these studies did not follow the scheme of sequence-dependent inhibition that we hypothesized to increase efficacy, the observations of increased toxicities in some of these studies were consistent with our findings. A separate study combining capecitabine plus oxaliplatin with erlotinib also did not observe toxicity differences between continuous versus intermittent dosing with chemotherapy, but noted 49 out of 60 patients having cycle delays during the study (34).

Maintenance therapy allows patients to take breaks from conventional chemotherapy that would have eventual doselimiting toxicities. Targeting EGFR with a TKI could theoretically be useful in the maintenance setting after induction treatment with chemotherapy with or without a biological agent. In the OPTIMOX3 study, patients with
Table III. Toxicities experienced by patients treated with second-line chemotherapy and erlotinib.

\begin{tabular}{ll}
\hline & $\mathrm{N}=11$ \\
\hline Grade 3 and 4 adverse events & \\
Neutropenia & $7(64 \%)$ \\
Diarrhea & $2(18 \%)$ \\
Liver function & $2(18 \%)$ \\
Oral pain & $2(18 \%)$ \\
Abdominal pain & $1(9 \%)$ \\
Fatigue & $1(9 \%)$ \\
GI bleed & $1(9 \%)$ \\
Hyponatremia & $1(9 \%)$ \\
INR elevation & $1(9 \%)$ \\
Nausea & $1(9 \%)$ \\
Rash & $1(9 \%)$ \\
Cycle delays and dose reductions & \\
Chemotherapy cycle delays & $9(82 \%)$ \\
Erlotinib dose reductions & $3(27 \%)$ \\
Erlotinib discontinuations & $3(27 \%)$ \\
\hline
\end{tabular}

metastatic colorectal cancer who had at least stable disease after bevacizumab-based combination chemotherapy were randomized to receive bevacizumab maintenance or bevacizumab plus erlotinib combination. However, progressive-free survival and overall survival were both only marginally increased in the combination group, and thus this approach has not been adopted in unselected patients (35). Perhaps biomarker-selected patient subsets may benefit. Nevertheless, until such biomarkers are identified, dual targeting of EGFR and angiogenesis in maintenance therapy without chemotherapy remains disappointing. Combination therapy with bevacizumab and cetuximab during induction chemotherapy did not show any synergistic activity (36), and subsequently the Nordic ACT2 trial found that bevacizumab plus erlotinib was no better than bevacizumab alone for maintenance therapy (37). Despite studies suggesting that there may be a role for first-generation EGFR TKI in metastatic colorectal cancer, we have yet to find a way to safely dose and schedule these agents with other therapies and to identify predictive biomarkers that could select patients who are most likely to benefit.

As new classes of agents have become available for metastatic colorectal cancer along with accompanying predictive biomarkers, yet another treatment strategy is to target multiple steps in the EGFR signaling pathway. For instance, the single-arm phase II DUX study, which used both cetuximab and erlotinib for previously treated patients with colorectal cancer, reported a response rate of $31 \%$ although high rates of rash and hypomagnesemia were noted (38). SWOG 1406 is an ongoing study that combines cetuximab and irinotecan with vemurafenib, a $B R A F$ 
Table IV. Clinical outcomes for all study patients treated with second-line chemotherapy and erlotinib.

\begin{tabular}{|c|c|c|c|c|c|c|}
\hline Patient number & $\begin{array}{l}\text { Months of therapy } \\
\text { (no. of cycles) }\end{array}$ & $\begin{array}{l}\text { Days on } \\
\text { erlotinib }\end{array}$ & $\begin{array}{l}\text { Discontinuation of } \\
\text { erlotinib due to } \mathrm{AE}^{*}\end{array}$ & $\begin{array}{l}\text { Dose reduction of } \\
\text { erlotinib required }\end{array}$ & $\begin{array}{c}\text { Reasons for } \\
\text { stopping therapy }\end{array}$ & $\begin{array}{l}\text { Days to } \\
\text { AE** }^{* *}\end{array}$ \\
\hline 1 & $2(4)$ & 24 & No & No & PD & 41 \\
\hline 2 & $4(8)$ & 48 & No & No & PD & 48 \\
\hline 3 & $0.5(1)$ & 6 & Yes & No & $\mathrm{PD}, \mathrm{AE}$ & 5 \\
\hline 4 & $1.5(3)$ & 9 & Yes & Yes & $\mathrm{PD}, \mathrm{AE}$ & 4 \\
\hline 5 & $6(12)$ & 71 & Yes & No & $\mathrm{AE}$ & 28 \\
\hline 6 & $0.5(1)$ & 6 & No & No & PD & 0 \\
\hline 7 & $4(8)$ & 48 & No & No & PD & 0 \\
\hline 8 & $2(4)$ & 24 & No & No & PD & 14 \\
\hline 9 & $2(4)$ & 41 & No & Yes & PD & 28 \\
\hline 10 & $4(8)$ & 48 & No & Yes & PD & 10 \\
\hline 11 & $2.5(5)$ & 30 & No & No & PD & 104 \\
\hline
\end{tabular}

PD: Progressive disease; AE: adverse events. *Prior to stopping chemotherapy; **grade 3 or 4.

inhibitor, in patients with $B R A F$-mutant metastatic colorectal cancer. It remains to be seen if EGFR TKIs can work synergistically with $B R A F$ inhibitors, and other mutations in the $R A S$ and $B R A F$ signaling pathways might predict response from this combination. It is also not known if newer-generation EGFR TKIs such as osimertinib may have better clinical efficacy and tolerability in metastatic colorectal cancer than erlotinib and gefitinib, as recently a pre-clinical study also demonstrated synergy between osimertinib and fluoropyrimidine (39). These investigations suggest that small-molecule inhibitors targeting the EGFR pathway remain promising in the correct setting.

Our study has several methodological limitations. Firstly, $K R A S$ testing was not available until after the study began, and the enrolled patients with KRAS mutation were perhaps unlikely to respond. This observation reflects the importance of characterizing predictive biomarkers when planning clinical trials that target specific signaling pathways. Additionally, most patients at our collaborating centers had been previously treated with first-line oxaliplatin-based therapy which significantly slowed accrual in the mFOLFOX/E arm. Indeed, FOLFIRI/E was the driver of toxicities in our study that led to termination. Thus, it remains possible that $\mathrm{mFOLFOX/E}$ may be more tolerable, and we cannot rule out that sequence-dependent mFOLFOX/E might have demonstrated increased efficacy.

\section{Conclusion}

With expanding treatment options for metastatic colorectal cancer, there remains a need for increasing efficacy in the later lines of therapy, when tumors become chemotherapy-resistant. For this reason, targeting specific signaling pathways, sometimes with multiple agents, serves as an exciting area of research. While we observed a combined response rate of $18 \%$ (two out of 11 patients) in this phase II trial testing erlotinib in combination with multi-agent chemotherapies, excessive toxicities and tolerability concerns ultimately caused significant cycle delays and treatment discontinuations. Identifying the optimal sequence of dosing these targeted agents with well-established chemotherapy backbones and robust biomarkers to select appropriate patients is essential. Newer, more tolerable EGFR TKIs and other drug targets along the EGFR pathway may ultimately serve as therapeutic options for patients with metastatic colorectal cancer.

\section{Funding}

This investigation is supported by funding from the OHSU Knight Cancer Institute and Genentech.

\section{Conflicts of Interest}

No Authors have conflicts of interest with the sponsors or any other organizations in this investigation.

\section{References}

1 Bray F, Ferlay J, Soerjomataram I, Siegel RL, Torre LA and Jemal A: Global cancer statistics 2018: Globocan estimates of incidence and mortality worldwide for 36 cancers in 185 countries. CA Cancer J Clin 68(6): 394-424, 2018.

2 Meta-analysis Group In C, Piedbois P, Rougier P, Buyse M, Pignon J, Ryan L, Hansen R, Zee B, Weinerman B, Pater J, Leichman C, Macdonald J, Benedetti J, Lokich J, Fryer J, Brufman G, Isacson R, Laplanche A and Levy E: Efficacy of intravenous continuous infusion of fluorouracil compared with bolus administration in advanced colorectal cancer. J Clin Oncol 16(1): 301-308, 1998.

3 Venook AP, Niedzwiecki D, Lenz H-J, Innocenti F, Mahoney MR, O'Neil BH, Shaw JE, Polite BN, Hochster HS, Atkins JN, Goldberg RM, Mayer RJ, Schilsky RL, Bertagnolli MM, Blanke 
CD; Cancer, Leukemia Group B S and ECOG: CALGB/SWOG 80405: Phase III trial of irinotecan/5-FU/leucovorin (FOLFIRI) or oxaliplatin/5-FU/leucovorin (mFOLFOX6) with bevacizumab (BV) or cetuximab (Cet) for patients (pts) with KRAS wild-type (wt) untreated metastatic adenocarcinoma of the colon or rectum (MCRC). J Clin Oncol 32(15 Suppl): LBA3-LBA3, 2014.

4 Colucci G, Gebbia V, Paoletti G, Giuliani F, Caruso M, Gebbia N, Carteni G, Agostara B, Pezzella G, Manzione L, Borsellino N, Misino A, Romito S, Durini E, Cordio S, Di Seri M, Lopez M, Maiello E, Montemurro S, Cramarossa A, Lorusso V, Di Bisceglie M, Chiarenza M, Valerio MR, Guida T, Leonardi V, Pisconti S, Rosati G, Carrozza F, Nettis G, Valdesi M, Filippelli G, Fortunato S, Mancarella S, Brunetti C and Gruppo Oncologico Dell'Italia M: Phase III randomized trial of FOLFIRI versus FOLFOX4 in the treatment of advanced colorectal cancer: A multicenter study of the Gruppo Oncologico dell'Italia Meridionale. J Clin Oncol 23(22): 4866-4875, 2005.

5 Yamazaki K, Nagase M, Tamagawa H, Ueda S, Tamura T, Murata K, Eguchi Nakajima T, Baba E, Tsuda M, Moriwaki T, Esaki T, Tsuji Y, Muro K, Taira K, Denda T, Funai S, Shinozaki K, Yamashita H, Sugimoto N, Okuno T, Nishina T, Umeki M, Kurimoto T, Takayama T, Tsuji A, Yoshida M, Hosokawa A, Shibata Y, Suyama K, Okabe M, Suzuki K, Seki N, Kawakami K, Sato M, Fujikawa K, Hirashima T, Shimura T, Taku K, Otsuji T, Tamura F, Shinozaki E, Nakashima K, Hara H, Tsushima T, Ando M, Morita S, Boku N and Hyodo I: Randomized phase III study of bevacizumab plus FOLFIRI and bevacizumab plus mFOLFOX6 as first-line treatment for patients with metastatic colorectal cancer (WJOG4407G). Ann Oncol 27(8): 1539-1546, 2016.

6 Heinemann V, von Weikersthal LF, Decker T, Kiani A, VehlingKaiser U, Al-Batran SE, Heintges T, Lerchenmuller C, Kahl C, Seipelt G, Kullmann F, Stauch M, Scheithauer W, Hielscher J, Scholz M, Muller S, Link H, Niederle N, Rost A, Hoffkes HG, Moehler M, Lindig RU, Modest DP, Rossius L, Kirchner T, Jung A and Stintzing S: FOLFIRI plus cetuximab versus FOLFIRI plus bevacizumab as first-line treatment for patients with metastatic colorectal cancer (FIRE-3): A randomised, open-label, phase 3 trial. Lancet Oncol 15(10): 1065-1075, 2014.

7 Ciardiello F, Normanno N, Martinelli E, Troiani T, Pisconti S, Cardone C, Nappi A, Bordonaro AR, Rachiglio M, Lambiase M, Latiano TP, Modoni G, Cordio S, Giuliani F, Biglietto M, Montesarchio V, Barone C, Tonini G, Cinieri S, Febbraro A, Rizzi D, De Vita F, Orditura M, Colucci G, Maiello E, Investigators $\mathrm{C}-\mathrm{G}$ and investigators $\mathrm{C}-\mathrm{G}$ : Cetuximab continuation after first progression in metastatic colorectal cancer (CAPRIGOIM): A randomized phase II trial of FOLFOX plus cetuximab versus FOLFOX. Ann Oncol 27(6): 1055-1061, 2016.

8 Peeters M, Price TJ, Cervantes A, Sobrero AF, Ducreux M, Hotko Y, Andre T, Chan E, Lordick F, Punt CJ, Strickland AH, Wilson G, Ciuleanu TE, Roman L, Van Cutsem E, Tzekova V, Collins S, Oliner KS, Rong A and Gansert J: Randomized phase III study of panitumumab with fluorouracil, leucovorin, and irinotecan (FOLFIRI) compared with folfiri alone as second-line treatment in patients with metastatic colorectal cancer. J Clin Oncol 28(31): 4706-4713, 2010.

9 Sobrero AF, Maurel J, Fehrenbacher L, Scheithauer W, Abubakr YA, Lutz MP, Vega-Villegas ME, Eng C, Steinhauer EU, Prausova J, Lenz HJ, Borg C, Middleton G, Kroning H, Luppi G, Kisker O, Zubel A, Langer C, Kopit J and Burris HA, 3rd:
Epic: Phase III trial of cetuximab plus irinotecan after fluoropyrimidine and oxaliplatin failure in patients with metastatic colorectal cancer. J Clin Oncol 26(14): 2311-2319, 2008.

10 Guinney J, Dienstmann R, Wang X, de Reynies A, Schlicker A, Soneson C, Marisa L, Roepman P, Nyamundanda G, Angelino P, Bot BM, Morris JS, Simon IM, Gerster S, Fessler E, De Sousa EMF, Missiaglia E, Ramay H, Barras D, Homicsko K, Maru D, Manyam GC, Broom B, Boige V, Perez-Villamil B, Laderas T, Salazar R, Gray JW, Hanahan D, Tabernero J, Bernards R, Friend SH, Laurent-Puig P, Medema JP, Sadanandam A, Wessels L, Delorenzi M, Kopetz S, Vermeulen L and Tejpar S: The consensus molecular subtypes of colorectal cancer. Nat Med 21(11): 1350-1356, 2015.

11 Williet N, Petcu CA, Rinaldi L, Cottier M, Del Tedesco E, Clavel L, Dumas O, Jarlot C, Bouarioua N, Roblin X, Peoc'h M and Phelip JM: The level of epidermal growth factor receptors expression is correlated with the advancement of colorectal adenoma: Validation of a surface biomarker. Oncotarget $8(10)$ : 16507-16517, 2017

12 Scartozzi M, Bearzi I, Berardi R, Mandolesi A, Fabris G and Cascinu S: Epidermal growth factor receptor (EGFR) status in primary colorectal tumors does not correlate with EGFR expression in related metastatic sites: Implications for treatment with EGFR-targeted monoclonal antibodies. J Clin Oncol 22(23): 4772-4778, 2004.

13 Porebska I, Harlozinska A and Bojarowski T: Expression of the tyrosine kinase activity growth factor receptors (EGFR, ERB B2, ERB B3) in colorectal adenocarcinomas and adenomas. Tumour Biol 21(2): 105-115, 2000.

14 Karapetis CS, Khambata-Ford S, Jonker DJ, O’Callaghan CJ, Tu D, Tebbutt NC, Simes RJ, Chalchal H, Shapiro JD, Robitaille S, Price TJ, Shepherd L, Au HJ, Langer C, Moore MJ and Zalcberg JR: $K$-RAS mutations and benefit from cetuximab in advanced colorectal cancer. N Engl J Med 359(17): 1757-1765, 2008.

15 Townsley CA, Major P, Siu LL, Dancey J, Chen E, Pond GR, Nicklee T, Ho J, Hedley D, Tsao M, Moore MJ and Oza AM: Phase II study of erlotinib (OSI-774) in patients with metastatic colorectal cancer. Br J Cancer 94(8): 1136-1143, 2006.

16 Fisher GA, Kuo T, Ramsey M, Schwartz E, Rouse RV, Cho CD, Halsey J and Sikic BI: A phase II study of gefitinib, 5fluorouracil, leucovorin, and oxaliplatin in previously untreated patients with metastatic colorectal cancer. Clin Cancer Res 14(21): 7074-7079, 2008.

17 Kuo T, Cho CD, Halsey J, Wakelee HA, Advani RH, Ford JM, Fisher GA and Sikic BI: Phase II study of gefitinib, fluorouracil, leucovorin, and oxaliplatin therapy in previously treated patients with metastatic colorectal cancer. J Clin Oncol 23(24): 56135619, 2005.

18 Meyerhardt JA, Stuart K, Fuchs CS, Zhu AX, Earle CC, Bhargava P, Blaszkowsky L, Enzinger P, Mayer RJ, Battu S, Lawrence C and Ryan DP: Phase II study of FOLFOX, bevacizumab and erlotinib as first-line therapy for patients with metastatic colorectal cancer. Ann Oncol 18(7): 1185-1189, 2007.

19 Hanauske AR, Cassidy J, Sastre J, Bolling C, Jones RJ, Rakhit A, Fettner S, Brennscheidt U, Feyereislova A and Diaz-Rubio E: Phase $1 \mathrm{~b}$ dose escalation study of erlotinib in combination with infusional 5-fluorouracil, leucovorin, and oxaliplatin in patients with advanced solid tumors. Clin Cancer Res 13(2 Pt 1): 523$531,2007$. 
20 Messersmith WA, Laheru DA, Senzer NN, Donehower RC, Grouleff P, Rogers T, Kelley SK, Ramies DA, Lum BL and Hidalgo M: Phase I trial of irinotecan, infusional 5-fluorouracil, and leucovorin (FOLFIRI) with erlotinib (OSI-774): Early termination due to increased toxicities. Clin Cancer Res 10(19): 6522-6527, 2004.

21 Chen J, Smith M, Kolinsky K, Adames V, Mehta N, Fritzky L, Rashed M, Wheeldon E, Linn M and Higgins B: Antitumor activity of her1/egfr tyrosine kinase inhibitor erlotinib, alone and in combination with CPT-11 (irinotecan) in human colorectal cancer xenograft models. Cancer Chemother Pharmacol 59(5): 651-659, 2007.

22 Ouchi KF, Yanagisawa M, Sekiguchi F and Tanaka Y: Antitumor activity of erlotinib in combination with capecitabine in human tumor xenograft models. Cancer Chemother Pharmacol 57(5): 693-702, 2006.

23 Dai Q, Ling YH, Lia M, Zou YY, Kroog G, Iwata KK and Perez-Soler R: Enhanced sensitivity to the HER1/epidermal growth factor receptor tyrosine kinase inhibitor erlotinib hydrochloride in chemotherapy-resistant tumor cell lines. Clin Cancer Res 11(4): 1572-1578, 2005.

24 Troiani T, Lockerbie O, Morrow M, Ciardiello F and Eckhardt SG: Sequence-dependent inhibition of human colon cancer cell growth and of prosurvival pathways by oxaliplatin in combination with ZD6474 (zactima), an inhibitor of VEGFR and EGFR tyrosine kinases. Mol Cancer Ther 5(7): 1883-1894, 2006.

25 Therasse P, Arbuck SG, Eisenhauer EA, Wanders J, Kaplan RS, Rubinstein L, Verweij J, Van Glabbeke M, van Oosterom AT, Christian MC and Gwyther SG: New guidelines to evaluate the response to treatment in solid tumors. European Organization for Research and Treatment of Cancer, National Cancer Institute of the United States, National Cancer Institute of Canada. J Natl Cancer Inst 92(3): 205-216, 2000.

26 Trotti A, Colevas AD, Setser A, Rusch V, Jaques D, Budach V, Langer C, Murphy B, Cumberlin R, Coleman CN and Rubin P: CTCAE V3.0: Development of a comprehensive grading system for the adverse effects of cancer treatment. Semin Radiat Oncol 13(3): 176-181, 2003.

27 Takabatake D, Fujita T, Shien T, Kawasaki K, Taira N, Yoshitomi S, Takahashi H, Ishibe Y, Ogasawara Y and Doihara $\mathrm{H}$ : Tumor inhibitory effect of gefitinib (ZD1839, iressa) and taxane combination therapy in EGFR-overexpressing breast cancer cell lines (MCF7/ADR, MDA-MB-231). Int J Cancer 120(1): 181-188, 2007

28 Chun PY, Feng FY, Scheurer AM, Davis MA, Lawrence TS and Nyati MK: Synergistic effects of gemcitabine and gefitinib in the treatment of head and neck carcinoma. Cancer Res 66(2): 981-988, 2006.

29 Van Cutsem E, Verslype C, Beale P, Clarke S, Bugat R, Rakhit A, Fettner SH, Brennscheidt U, Feyereislova A and Delord JP: A phase IB dose-escalation study of erlotinib, capecitabine and oxaliplatin in metastatic colorectal cancer patients. Ann Oncol 19(2): 332-339, 2008.

30 Meyerhardt JA, Zhu AX, Enzinger PC, Ryan DP, Clark JW, Kulke MH, Earle CC, Vincitore M, Michelini A, Sheehan S and Fuchs CS: Phase ii study of capecitabine, oxaliplatin, and erlotinib in previously treated patients with metastastic colorectal cancer. J Clin Oncol 24(12): 1892-1897, 2006.
31 Bajetta E, Di Bartolomeo M, Buzzoni R, Ferrario E, Dotti KF, Mariani L, Bajetta R, Gevorgyan A, Venturino P and Galassi M: Dose finding study of erlotinib combined to capecitabine and irinotecan in pretreated advanced colorectal cancer patients. Cancer Chemother Pharmacol 64(1): 67-72, 2009.

32 Kozuch P, Malamud S, Wasserman C, Homel P, Mirzoyev T and Grossbard M: Phase ii trial of erlotinib and capecitabine for patients with previously untreated metastatic colorectal cancer. Clin Colorectal Cancer 8(1): 38-42, 2009.

33 Santoro A, Comandone A, Rimassa L, Granetti C, Lorusso V, Oliva C, Ronzoni M, Siena S, Zuradelli M, Mari E, Pressiani T and Carnaghi C: A phase II randomized multicenter trial of gefitinib plus folfiri and folfiri alone in patients with metastatic colorectal cancer. Ann Oncol 19(11): 1888-1893, 2008.

34 Ma BB, Chan SL, Ho WM, Lau W, Mo F, Hui EP, Chan C, Poon A, Dattatray RD, Wong SC, To KF, King AD, Ahuja A and Chan AT: Intermittent versus continuous erlotinib with concomitant modified "XELOX" $(q 3 w)$ in first-line treatment of metastatic colorectal cancer: Correlation with serum amphiregulin and transforming growth factor alpha. Cancer 119(23): 4145-4153, 2013.

35 Tournigand C, Chibaudel B, Samson B, Scheithauer W, Vernerey D, Mesange P, Lledo G, Viret F, Ramee JF, Tubiana-Mathieu N, Dauba J, Dupuis O, Rinaldi Y, Mabro M, Aucoin N, Latreille J, Bonnetain F, Louvet C, Larsen AK, Andre T and de Gramont A: Bevacizumab with or without erlotinib as maintenance therapy in patients with metastatic colorectal cancer (GERCOR DREAM; OPTIMOX3): A randomised, open-label, phase 3 trial. Lancet Oncol 16(15): 1493-1505, 2015.

36 Tol J, Koopman M, Cats A, Rodenburg CJ, Creemers GJ, Schrama JG, Erdkamp FL, Vos AH, van Groeningen CJ, Sinnige HA, Richel DJ, Voest EE, Dijkstra JR, Vink-Borger ME, Antonini NF, Mol L, van Krieken JH, Dalesio O and Punt CJ: Chemotherapy, bevacizumab, and cetuximab in metastatic colorectal cancer. N Engl J Med 360(6): 563-572, 2009.

37 Hagman H, Frodin JE, Berglund A, Sundberg J, Vestermark LW, Albertsson M, Fernebro E and Johnsson A: A randomized study of KRAS-guided maintenance therapy with bevacizumab, erlotinib or metronomic capecitabine after first-line induction treatment of metastatic colorectal cancer: The Nordic ACT2 trial. Ann Oncol 27(1): 140-147, 2016.

38 Weickhardt AJ, Price TJ, Chong G, Gebski V, Pavlakis N, Johns TG, Azad A, Skrinos E, Fluck K, Dobrovic A, Salemi R, Scott AM, Mariadason JM and Tebbutt NC: Dual targeting of the epidermal growth factor receptor using the combination of cetuximab and erlotinib: Preclinical evaluation and results of the phase II DUX study in chemotherapy-refractory, advanced colorectal cancer. J Clin Oncol 30(13): 1505-1512, 2012.

39 Guo L, Huang S and Wang X: Puma mediates the anti-cancer effect of osimertinib in colon cancer cells. Onco Targets Ther 10: 5281-5288, 2017. 